\title{
THE HISTORY AND TRENDS OF COUNSELING IN JAPAN
}

\author{
Osamu TABATA \\ (Nagoya University)
}

\begin{abstract}
It was after World War II that counseling was introduced into Japan. A great deal has been learned from the United States in this field and then from Europe also. Summarized here is the history of a practice, called counseling, in Japan up to the time when the authorization system of qualified counselors has been established. Counseling in the future is also considered.

Key words: World War II, SPS (Student Personnel Services), mental health, life cycle, certification.
\end{abstract}

\section{Introduction}

In this paper, a discussion on how counseling, a professional helping practice, had been developed and conducted in Japan. In doing so, it is favorable, to divide the time of our concern into several distinct periods while mentioning the characteristics of counseling in each period, in relation with the historical background of the period. That should help understand the overview of the development from all angles.

Based on an English paper I presented at the 22nd Congress of the International Applied Psychology Association held in July, 1990 at Kyoto (Tabata, 1990), the following article will focus mainly on the development of counseling in Japan.

\section{The First Period 1945-1957: The Introduction of Counseling and the Beginning of its Practice in Japan}

It is said that counseling, a professional helping practice, began to be conducted in Japan after 1945 after the end of World War II. Although we had at that time Child Guidance Centers and research institutes for childhood issues, such centers will not be considered here.

The end of World War II brought about changes the Japanese way of thinking as a basis of counseling and, above all, the way of looking at human beings.

In 1946, soon after the end of the Second World War, American educational missions visited Japan to recommend us to reject the totalitarian approach toward education adopted until then and to implant a more liberal and democratic approach. What the new approach emphasized was the establishment of an educational system which could promote the independence of individual thinking, the development of individuality and democratic rights and responsibilities of citizens, on the assumptions that individual value should be respected and that individual differences should be recognized. Needless to say, the new educational system we now have: six years in elementary school, three years in junior high school and another three in senior high school (the "6-3-3 System"), followed by a four-year college.

The recommendations of the missions naturally included an idea of guidance functioning, i.e. counseling. Guidance would help individuals to understand their abilities and interests, to set goals, and finally, to achieve a matured self-control as favorable citizens in a democratic society. This idea is consistently observed in today's counseling. Following the recommendations, many books and magazines on guidance were published. In the educational circle, seminars to better train teachers started to cover the field of guidance in many parts of Japan. I myself well remember teachers with straw hats on saying then, "What kind of dance is guidance?" on the way to a retraining seminar.

Counseling, in a narrow sense, has its root in what influenced Masashi Masaki, then a professor of the Tohoku University and later of the Department of Education, Kyoto University i.e., the principle of Carl R. Rogers, or the nondirective counseling, through Aurther T. Jersild, a child psychologist, who visited 
Japan to lecture on a special seminar for educational instructors. Professor Masaki is said to have been much enlightened by the nondirective method, now call client-centered therapy or counseling. Two years after he was transferred to Kyoto University in 1952, he founded an educational counseling clinic where he, together with his colleague, Professor Seiichi Kuraishi, started supervising clinical practical trainings for graduate students.

In the 1950's, five lecturers led by W.P. Loyd visited Japan to grope for a new approach to Student Personnel Services (SPS) through various programs. Between 1952 and 1953, a research assembly on SPS was held at Kyoto University, Kyushu University and the University of Tokyo. The college faculties and officials who participated in the gatherings had enthusiastic discussions and arguments on the subject for the following three months. The necessity of SPS was recognized at the assembly, which led to the establishment of the Japan's first counseling centers for students on both Hongo and Komaba campuses, the University of Tokyo from 1953. Then, such national universities as Yamaguchi University, Kyoto University, Tohoku University and Nagoya University, together with private universities such as Rikkyo University, Keio University, Gakushuin University and Japan Women's University were seen establishing counseling centers for students.

Also in 1955, W.P. Loyd, F.P. Robinson and E.S. Bordin visited Japan to have the same sort of assemblies as mentioned above. Participants were intensively trained for about three months, proving a big step forward in researches and practices of counseling (Matsubara, 1991). In 1956, E.G. Williamson, who was well-known for clinical counseling, also visited Japan and offered a three-month-long intensive course on "Theories and Practice of Counseling" at the University of Tokyo. His approach was called directive counseling or clinical counseling.

We have been looking at counseling in its beginning, its first period of development in Japan, while putting emphasis on what was taking place in the educational circles including secondary and higher education. As you might see, counseling in Japan has developed, mainly lead by universities. At its beginning, authorities from the United States sawed the seed of a practice of proper counseling in Japanese soil.

In the period of confusion and poverty following the war, Japan got to start on political reform. The idea of counseling and guidance was introduced into the new education system. The visit of an educational mission and the invitation of American authorities to research gatherings on SPS (Student Personnel Services) encouraged positive discussions. Universities opened counseling centers. A significant new period was in the making.

\section{The Second Period 1958-1968: The Rise of Coun- seling Movements}

In the following period, Japan increased its political and economic strength, and became a member of the international economic society. Japan implemented the doubling income policy and proudly held the 18th Olympic Games in Tokyo in 1964. People worked hard and courageously.

School education introduced so excessive a curriculum that some students were unable to master it. Such neurotics as dropouts and those refusing to attend school began to emerge. Human relationship at home was overshadowed by rapid economic growth. At school where students were to compete harshly, the perfectionists and the nervous started complaining of bad physical conditions and mental symptoms appeared. There were sufferings from bodily resistance toward school. College entrance examinations became too much of a hurdle to overcome easily. Words such as "examination hell" began to be widely used. The number of students entering high school increased, and even college education was considered a "must" to everyone. However, not all students could get into competitive colleges. A psychiatrist called this phenomenon the "Narrow Gate Syndrome". This phenomenon became a characteristic of Asian countries such as Japan, South Korea, Hong Kong and Taiwan. Besides these changes in the educational circle, problems such as pollution and environmental destruction broke out in the intense effort to become a full -fledged member of a competitive international economic society. Factories discharged smoke and waste water harming human health and polluting the sea. Deforestation became serious, and the problems 
of pollution piled up. The Japanese were called "economic animals" abroad, because of the Japanese companies being notorious for their ruthless manners to compete.

Now, let us take a look at how counseling developed under these socioeconomic conditions.

The year of 1961 became a landmark in the development of counseling. First, the "counseling section" was established in the Japanese Association of Applied Psychology. Along with it, leading scholars in psychotherapy such as C.R. Rogers and D.E. Super visited Japan from the United States.

Above all, the visit of Rogers had a strong impact on the educational and industrial circles. He was the one who was strenuous and active in both practice and research of "nondirective counseling" and/or "client -centered therapy". During his two-month-long stay from March, 1961, he enthusiastically fulfilled his schedules of lectures and seminars in many parts of the country.

While in Japan, in the United States, he was engaged in a big project to demonstrate whether his "client-centered therapy" could work well on those suffering from schizophrenia, under the cooperation of the Institute of Psychiatry at the University of Wisconsin and Mendota Hospital. On the other hand, in Japan, his "nondirective method" was being studied. The "nondirective method" was widely accepted and called cynically as "nondire". Unfortunately, some learners, however, understood this method as something in which those complaining of mental problems would be cured only if counselors listened to or approved them, saying, "Aha" or "Yes".

Rogers made his healing theory public in a professional journal in 1957. In the article, he explained attitudes of therapists to their clients and the conditions of the clients, relating them to necessary and sufficient conditions for personality changes in therapy. This theory is very simple to understand, but its practice is extremely difficult.

The impact of Rogers was enthusiastic. Although the author named this period "The Rise of Counseling Movement", it even might be essentially called a "nondirective counseling movement" or a "client -centered therapy movement".

What he left in Japan was incorporated into plan- ning, management and contents of counseling workshops: it could be added that it became widely practise in Japan. I, myself, can vividly remember some contents of a Rogers' lecture and tape-recorded role -playing I listened to in a liberal atmosphere at a counseling workshop held at the inn of the Enryakuji Temple in the Hiei Mountain. We still hold many counseling workshops, following the same planning and management style of those days.

The client-centered therapy of Rogers surely gave such a strong impact that it is now regarded as the mainstream. However, it would be like putting the cart before the horse if learning superficial counseling techniques without understanding therapeutic theory on how a therapist looks at a human-being and helps him to grow. Prudence is indispensable when this therapeutic method is applied.

Yet, it is noteworthy to remember that two academic associations were founded in this period. One was the Japanese Association of Clinical Psychology (1964), and another the Japanese Association of Counseling Science (1967). The latter was later renamed the Japanese Association of Counseling in 1987. These associations have not only covered researches and presentations of studies on counseling but also taken up such issues as training and authorization of qualified counselors. Also in 1957, the Japanese Society of Industrial Counselors was founded to start training industrial counselors.

\section{The Third Period 1969-1974: Contradictions and Struggles; The movement for Welfare of the Handicapped}

The societal background of this period was considerably bustling and unstable. The breakout of the Vietnam War (1959-1975) gave a rise to antiwar movements and strifes, mainly led by students, worldwide. The Great Cultural Revolution shook China, and the medical strife joggled Japan.

The political and economic situation was characterized by freed dollars in 1972, the oil crisis in 1972 and the subsequent devaluation of the Yen.

The academic circle witnessed a struggle between old traditional thinking and theory, and the new ones. In the Japanese Association of Psychiatry, psychic -social oriented psychiatrists began to part from those 
with the biological orientation of the traditional Kraepelin school. Yet the so-called "university dispute" spread all over Japan. One of the issues the dispute took up was the struggle for the promotion of welfare of the socially weak. Above all, radical activists fought for the abolition of discrimination, segregation, resentment, etc., against the handicapped.

The Japanese Association of Clinical Psychology mentioned above was also strongly influenced by the sequences of these cataclysmic changes. The establishment of the "Certification System for Professionals of Psyche" was suspended, although it had been a long pursued goal. The Association itself fell into what E.H. Erikson called an "identity crisis".

In the field of counseling, this marked the first period in which those who had received education and training in counseling in such countries as the United States and Switzerland returned to Japan. They introduced ideas and skills of counseling different from those of the Rogers' school. Then, some Japanese started to advocate truly helping people, on firm theoretical bases. Hayao Kawai was a pioneer. His article, "The Development of Psychotherapy and Significance of Rogers' Theory in Japan" (1970), well showed the situation of counseling in Japan. He introduced Jungian theory through many writings and educational analyses (dream analyses) he himself conducted. His impact has been tremendous. $\mathrm{He}$ studied at the Jung Institute in Zürich, Switzerland, and came home after becoming the first qualified Japanese counselor.

Yet, M.Tatara received education and training from the neo-psychoanalysis school. Besides, Minoru Hatase (1990) came back to Japan in 1969, having experiences the person-centered approach, or PCA, which promoted growth and development of healthy people. The practice of PCA was for him a complete diversion from his previous "challenge". He had been trying to apply the "Basic Encounter Group" method, one of the client-centered therapy Rogers began to put into practice on the West Coast in the late 1960 's, to schizophrenics.

In the Encounter method, clients, divided into groups of ten to twelve members, met intensively from six to ten times for a few hours per meeting.

This method had its root deeply in Rogers' under- standing of human-beings stating that a human-being gets rid of defense, gropes for his real self and is liberated in a liberal and warm psychological environment.

These returnees gradually demonstrated their uniqueness, gradually penetrating Japan. It would flourish in future periods.

\section{The Fourth Period 1975-1986: Toward A New Potential Movement}

During this period, Japan as a full-fledged member of the international society, with the recognition of the expectant advent of the aged society, started to pay a great deal of attention to welfare, under a sluggish economic condition. People began to pursue the richness of the mind and human nature rather than to try to fulfill a material desire for things including daily necessities. Yet, the society and the educational circle were calm and stable as a whole. The university dispute ending, students became apathetic and seemed empty. They indulged in play and showed infantilism.

On the other hand, many cases of domestic and school violence started to be reported (Domestic violence refers to violence mainly by adolescent boys) from the late 1970's. Also, the number of students who refused to go to school steadily increased. This phenomenon spread not only in urban areas but also in rural areas. Then, the problem of "bullying and bullied students" appeared while school violence became inconspicuous. Not a few bullied students tragically committed suicide to give up living at an early stage. Moreover, juvenile deliquency increased to hit the third peak widely recognized as part of education and social problems.

In the business circle, such psychological disorders as depression and resistance to go to work came to the surface. It was widely known in the world that the Japanese were very industrious, patient and hardworking. They collectively showed these characteristics as personnel of a company. However, "Karoshi", or death from excessive labor, attracted attention, and everyone now must have heard the words, the "burn-out syndrome".

Lately, these psycho-behavioral problems have become more complex and serious than ever. They 
arise not only from a single factor or cause but from a complex of both microscopic and macroscopic factors. Therefore, there is a great need for therapeutic and helping counseling truely working on clients and their families. Such counseling must be made of various approaches and perspectives, and, above all, "experts of mind". In the course of development of counseling, careful consideration has begun to be given to adequate education and training, and basic learning, both theoretical and practical; such factors are necessary to become a counselor.

A new academic association was established to respond effectively to the social and individual needs of anybody. Academic associations, both new and old, began to pay a great deal of attention to the issue of "authorization" of bequalified counselors. It was until lately that local autorities, academics, and, sometimes, priests tried to solve problems of the mind of residents in their areas. That is, the need for "experts of mind" could not be ignored, and its authorization was indispensable.

In the psychological circle, the Association of "Japanese Clinical Psychology" came to being in 1982 to tackle the issue of the authorization system. The first step forward was made in 1978 when the issue was included in the agenda of a symposium at the Japanese Association of Psychology. The "assembly of psychological counselors" was first held during the following year. The number of participants in the assembly increased from year to year, which eventually led to the foundation of the Association of Japanese Clinical Psychology in 1982. Those who received full-fledged education and training of counseling and qualifications for it played the central role in organizing such committees as the Educational Training Committee, the Committee on Graduate Carriculum and the Ethics Committee toward the establishment of the authorization system. Thus, the basis of the establishment was rapidly and steadily formed. What accelerated the process greatly were the facts that Japanese "experts of mind" ragged far behind counterparts in other countries; that there were no regulations on practice of counseling in such a way that qualified counselors in various occupational domains could realize their social responsibility other than rules imposed by each working place; and that "problems of mind" became too conspicuous to be easily taken easy. As we have seen so far, the need for an authorization system became so great that the establishment of the system was put smoothly into motion.

The Japanese Association of Humanistic Psychology was also founded in 1982 to give out studies, and to hold symposiums on many various themes concerned with humanity. Yet, the Japanese Association of Counseling Science established the system of authorization of counselors by the association in May, 1986 . Thus, academic associations concerned with counseling, independently or unitedly, had striven for the establishment of the authorization system since late 1980's.

\section{The Fifth Period 1987-today: Toward True Mental Health}

All through the past forty years, Japan has steadily developed economically. However, nuclear families have increased and the society itself has been aging, people feeling isolated, and fathers have been seen apart from their families for years on business. Yet, with the society being "internationalized", the number of families living abroad and returning students growing, international students have increased. Some of them have found difficulties in "cross-cultural" communication failing to adapt themselves to new surroundings. With the advent of the "information age" and the "control-oriented" society, people have become more alienated. Numerous problems concerning mental health and social welfare have arisen in every age group from infants to the aged, groups living in all spheres of life from home, school, working places, community to cross-cultural domains.

In this rapidly changing society, the Mental Health Law was amended in 1987, the Social Workers Law and the Homehelpers Law were enacted in May of the same year. Then a test to obtain a qualification for social work was first given by the government. Synchronizing with this move, the Japanese Society of Certified Clinical Psychologist was founded in March, 1988 under the cooperation of fifteen (later, nineteen) academic associations concerned to put forth authorized counselors in the Japanese society.

It has been no more than 40 years since counseling 
was introduced in Japan. Ideas and skills of counseling have widely penetrated in all stages of education, first in higher education and then in elementary and secondary education. Besides, today, counselors put their skills and knowledge at the disposal of any institutions serving therapeutic assistance such as hospitals, mental health centers, etc.; also in the Family Courts, juvenile detention homes, reformatories, prisons, etc.; health centers, counseling rooms, personnel departments, etc. in companies; child guidance centers, consultation centers for rehabilitation of the handicapped, woman consultation centers, outpatient facilities for short-term treatment of the mentally retarded, etc. found mainly in public and social welfare; also other institutes of such areas as religion, nursery, nursing, and cross-cultural counseling, and private practice.

Practice of counseling today covers a very wide range of people from those complaining of serious and complex psychological problems to those who have relatively healthy psychological lives. Qualified counselors try to meet a great variety of demands.

Moreover, some people receive counseling at certain places during certain periods of time in order to promote positive mental health though they do not have any problems with their mental health. The "Basic Encounter Group" as a collective experience mentioned above well represents a type of helping practice serving these people. Serious neurotics though are advised to avoid the above type. For, through this method, they would rather tend to aggravate their problems, or they might give trauma to other members of their groups. Experienced qualified facilitators are indispensable to manage the basic encounter groups smoothly.

As we have seen, today's counseling, on the one hand, consists of such "therapy-oriented models" as psychotherapy which helps those who have problems with mental health in the course of diagnosis and therapy. On the other hand, it includes "educational -development-oriented models" which positively promote humanistic growth and development of individuals and groups. That is, it could be compared to a baseball defense which covers a wide range of area from an infield to an outfield.

The wide spectrum of today's counseling is said to comprise innumerable elements, either implanted from other countries or originally developed in Japan. Akihiko Haga (1991) clarifies characteristics and problems of each school of counseling currently being practiced in Japan. Let us take a brief look at the different schools mentioned below.

(1) The directive school; (2) The non-directive school called today the "person-centered approach"; (3) The analysis school; (4) The Jungian school; (5) The behavioral school; (6) The Gestalt school; (7) Naikan therapy; (8) Morita therapy; (9) Encounter groups; (10) Psychodramas; (11) The transactional analysis; (12) Family therapy.

While counseling is practiced through verbal communication as a means, "play therapy" is used for infants and children.

It is critical not only to look back at the history of such development of counseling but also to have a perspective for future counseling.

\section{The Future Prospect for Counseling in Japan: Expansion and Deepening}

Finally, I would like to mention the future development of counseling in Japan. Counseling will be applied more widely and deeply.

Sugitani (1993) puts the possible development of counseling in the following six points on which I agree.

1) Life cycle and counseling;

2) Diversification and specialization of counseling activities;

3) Promotion of preventive, developmental counseling;

4) Spread of counseling mind and the group approach;

5) Roles of counselor and networking;

6) The integration of counseling theories, research and development.

A counselor, as an expert, must improve both knowledge and techniques, but what is more indispensable is his or her "therapeutic self".

The followings are issues we should put on the agenda for further discussions. 
1. Counseling should contribute to the well-being and mental health of those who need it.

2. Counselors should be educated and trained adequately and always work hard to improve their attitudes and skills with the recognition of their responsibility and significance in the society. They should learn without falling in dogmatic thinking.

3. Since it is impossible to be well versed in the theories of all the numerous schools, a counselor should pick up one school and expand his or her knowledge and skills into a wider range gradually.

4. If possible, a counselor should try to create something unique. Many unique branch schools were born from the theory of S. Freud.

5. A counselor should engage in clinical study and research. Possible methodology ranges from case studies to survey and statistical studies. The selection of a methodology depends on what he or she is concerned with.

6. Finally, a counselor should keep in mind to be humble enough to learn from his or her clients. In today' s complexity, clients come to see someone with such flexible thinking and attitude.

\section{Reference}

Fukuhara, M., 1989 Counseling Psychology in Japan, Applied Psychology: An International Review, 38(6) 409-422.

Haga, A., 1991 Gakkou Kaunseringu no Nagare to Tenbou (The Trends and Prospects of School Counseling), Tokushima Publishing Center.
Hatase, M., 1990 Enkauntaa Guruupu to Shinriteki Seichou (Encounter Group and Psychological Growth), Sougensha.

Kawai, H., 1970 Nihon niokeru Shinriryouhou no Hatten to Rogers Riron no Igi (The Development of Psychotherapy and the Significance of Rogers' Theory in Japan), Kyouiku to Igaku (Education and Medicine), 18(1) 11-16.

Matsubara, T., 1991 Nihon no Gakusei Soudan Katsudou no Rekishi (The History of Japanese Student Counseling), Gendai no Esupuri, Kyampasu Kaunsering (Modern Esprir, Campus Counseling), Zenkoku Gakusei Soudan Kenkyuu Kaigi Hen (Japan National Student Counseling Research Conference Ed.), Dec. (Vol. 293), 61-86.

Rogers, C. R., 1957 The Necessary and Sufficient Conditions of Therapeutic Personality Change, Journal of Consulting Psychology, 21, 95-105.

Saji, M., and Inaga K., (Eds.), 1983 Rogers Kuraiento Chuushin Ryouhou (Rogers, Client-centered Therapy), Yuuhikaku Sensho.

Sugitani, K. 1993 Counseling in Japan - Review and prospect. Japanese Journal of Counseling Science, 26, 75-85.

Tabata, O., 1990 Some Issues of Mental Health in Japan, Symposium: Mental Health Issues Confronting Asians in Different Societies, 22nd International Congress of Applied Psychology, Kyoto.

Uchiyama, K., Takano, S., and Tabata, O., (Eds.), 1984, Kaunsering (Counseling), Nihon Bunka Kagaku Sha. 